\title{
Preface
}

\section{International Conference on Structural Engineering Dynamics - ICEDyn 2009}

The International Conference on Structural Engineering Dynamics (ICEDyn 2009) took place in Ericeira, Portugal, on the $22^{\text {nd }}-24^{\text {th }}$ of June 2009, organized by the Instituto Superior T écnico (IST), from the Technical University of Lisbon, and the Instituto de Engenharia Mecânica (IDMEC). This conference embraced a large spectrum of subjects that attracted the interest of a wide community devoted to Engineering Dynamics, where theory and experiment mix very well. A significant number of senior scientists, representatives of the industrial community and young students developing their Master or Ph.D studies could meet together, interacting in a quite stimulating and fruitful atmosphere, sharing the same kind of interests and objectives. The conference model was based on a two and a half days of technical presentations, structured into two parallel sessions. Four international renowned scientists have addressed keynote lectures that preceded and framed the parallel sessions.

The present special issue for the Shock And Vibration journal has been carefully prepared, in order to meet the high standards of this publication and it reflects the major outcomes of ICEDyn 2009. From the 64 papers that have been presented, from participants from 17 different countries all over the world, 33 have been pre-selected for the special issue; the authors submitted improved versions of their articles and from those, 5 have been rejected and 28 approved, after passing through a rigorous peer review process with at least 2 independent reviews. These 28 papers cover various areas, from modal updating to non-linear dynamics, passing by damage detection, modal identification, modeling of damping, etc. It was a pleasure and an honor to have served as Guest Editors of SAV.

Acknowledgements are due to all the authors and co-authors, to the reviewers for all their time and collaboration and naturally to Prof. Daniel Inman, Editor-in-Chief of SAV, for his interest and enthusiasm in supporting this special issue.

Nuno M. M. Maia Miguel M. Neves Guest Editors

Instituto Superior Técnico Dept. Eng a Mecânica Av. Rovisco Pais, 1049-001 Lisbon Portugal 

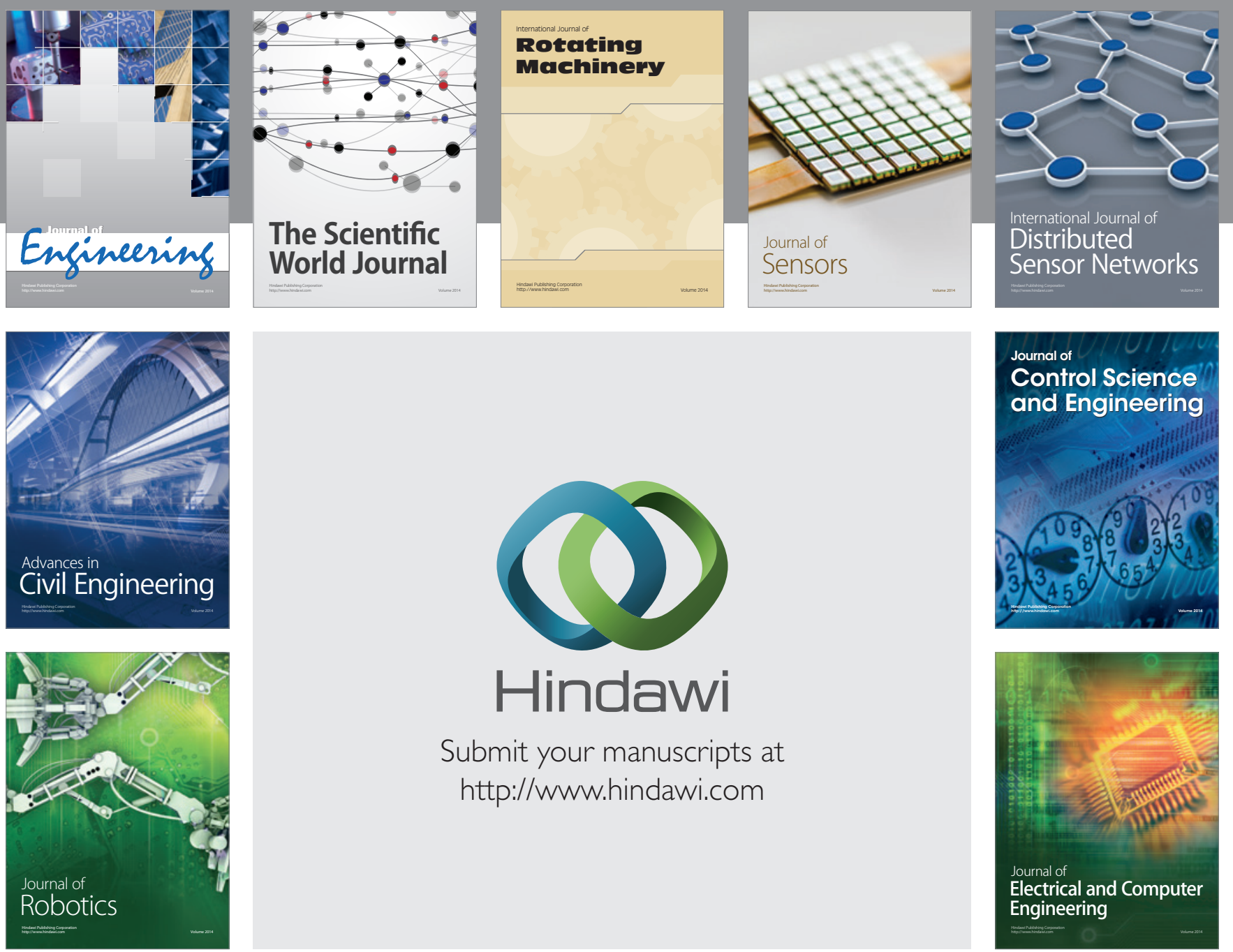

Submit your manuscripts at

http://www.hindawi.com
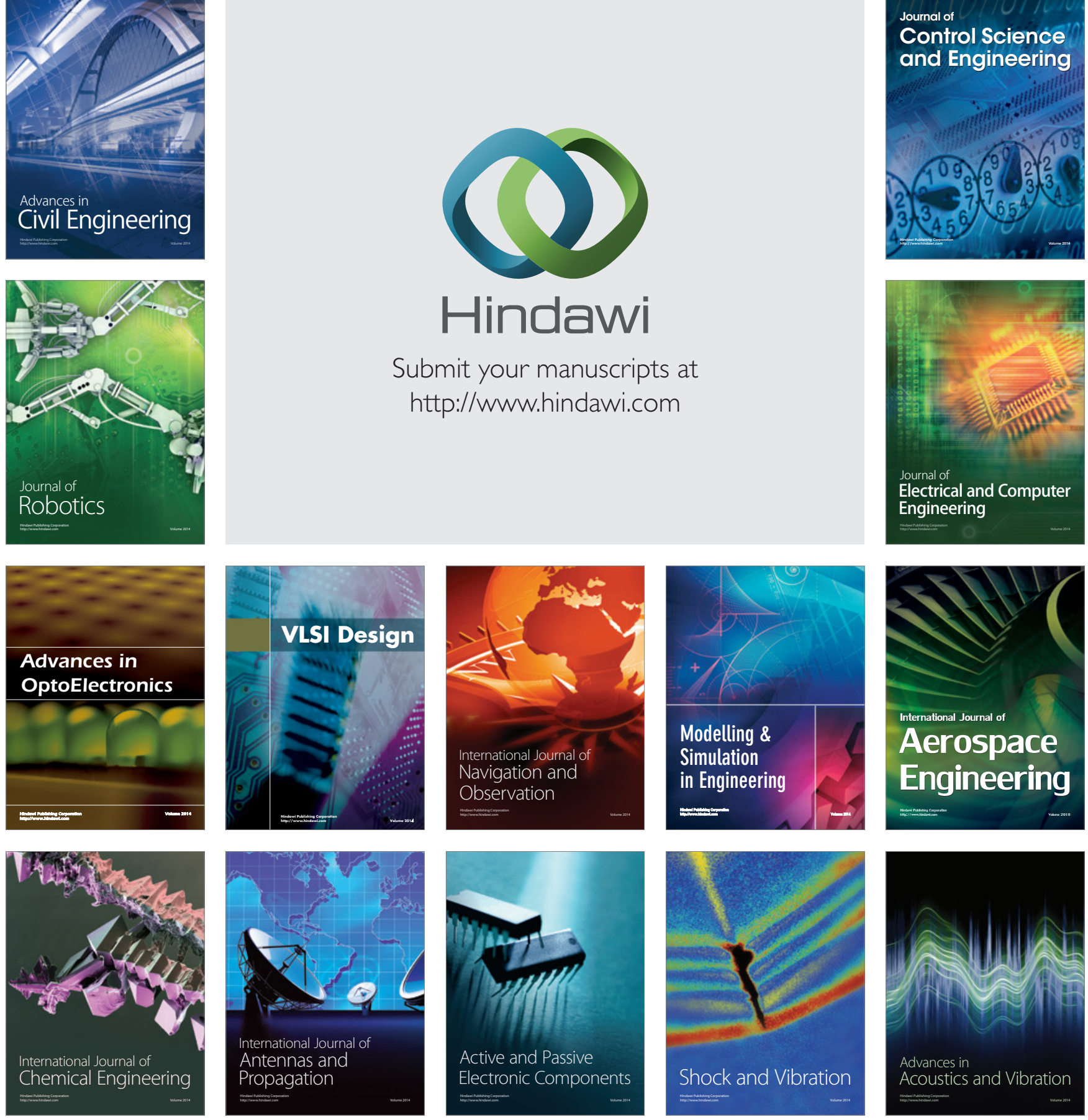